\title{
As políticas públicas de cooperação internacional em C\&T: uma análise particular
}

\author{
The international Science and Technology Cooperation Policy: a unique analysis
}

\author{
Amanda Almeida Domingues \\ Mestranda do Departamento de Política Científica e \\ Tecnológica \\ Universidade Estadual de Campinas - UNICAMP \\ e-mail: amandadomingues@ige.unicamp.br

\section{Maria Conceição da Costa} \\ Professora Associada do Departamento de Política \\ Científica e Tecnológica \\ Universidade Estadual de Campinas - UNICAMP \\ e-mail: dacosta@ige.unicamp.br
}

\begin{abstract}
RESUmo Abordando as especificidades da Política Científica e Tecnológica (PCT) e das Políticas de Cooperação Internacional em C\&T (PCIC\&T) e demonstrando a importância do Estado para o campo da C\&T como provedor de apoio institucional e financeiro, bem como os desafios que enfrenta atualmente, este trabalho apresenta o campo de Análise de Políticas como uma abordagem interessante para a análise das PCIC\&T. No artigo, são apresentados os principais modelos de Análise de Política e suas contribuições para o estudo das PCIC\&T, levando em conta as especificidades destas. Além disso, a cada modelo, são associadas teorias do campo de Relações Internacionais que oferecem um suporte teórico importante de análise.
\end{abstract}

PALAVRAS-ChaVe Ciência e Tecnologia; Cooperação Internacional; Políticas Públicas.

ABSTRACT This article introduces Policy Analysis field as an interesting alternative to investigate International Science and Technology Cooperation Policy (IS\&TCP). The work describes the specificity of Science and Technology Policy, in addition to detailing the challenges that States currently face and referring to them as essential providers of institutional as well as financial support to Science and Technology actors. The main Policy Analysis models are presented as well as their contribution to the IS\&TCP investigation, considering the specificities already mentioned. To each of these models we associate theories from the International Relations field, which provide an important theoretical basis for analysis.

KEYWORDS Science and Technology; International Cooperation; Public Policy. 


\section{Introdução}

A partir dos aos 80 do século $\mathrm{XX}$, os atores envolvidos com a Política Científica e Tecnológica (PCT) constataram a importância da cooperação internacional para a construção de capacidades em ciência e tecnologia $(C \& T)$ e para o aprimoramento da pesquisa. Diversos fatores internacionais, como a emergência dos BRICS, a urgência de desafios internacionais importantes - como a mudança climática e a energia nuclear - a globalização da $\mathrm{P} \& \mathrm{D}^{1} \mathrm{e}$ a facilidade nas comunicações incentivaram os atores nacionais a reforçar e aumentar as atividades de cooperação internacional que empreendiam na área de C\&T.

Reconhecendo a importância do campo como uma porta de entrada para outras relações, nos âmbitos econômicos e políticos, a C\&T passaram a tomar a agenda de governos não somente nos níveis nacionais, mas também nos subnacionais. Atraiu também a atenção de Instituições de Pesquisa e de Ensino Superior, bem como de agências de fomento que financiam suas atividades internacionais. Assim, uma série de políticas públicas foram implementadas no sentido de fomentar essa cooperação, assegurando que o país desfrute dos benefícios gerados. O estudo destas políticas gera um desafio duplo: primeiramente compreender a especificidade da PCT, que se apresenta como um caso especial dentre o universo das políticas públicas; e em segundo lugar, compreender a singularidade de políticas para cooperação internacional em C\&T que ainda apresentam importantes deficiências.

Neste contexto, este artigo pretende apresentar estas particularidades da PCT para cooperação internacional, definindo-a como uma política pública diferenciada que envolve diversos atores, principalmente em seu âmbito internacional. O trabalho pretende também contribuir para a análise e investigação destas políticas, propondo abordagens apropriadas advindas do campo de Análise de Política. Para alcançar esses objetivos é necessário ter em mente que o Estado é um ator chave na análise das políticas de cooperação internacional em C\&T (PCIC\&T), não somente no âmbito da sua atuação no ciclo da política (como formulador, executor e avaliador destas políticas), mas também como um ator participativo, que fomenta a cooperação financeiramente. Além

\footnotetext{
Segundo o relatório da OCDE (2008), a globalização da P\&D consiste na atuação cada vez mais internacional de funções corporativas intensas em conhecimento. A crescente competição global em inovação e o custo das atividades de P\&D (devido ao seu caráter cada vez mais multidisciplinar) levaram instituições a procurarem fontes externas de inovação, bem como alianças estratégicas externas, fusões e aquisições, corporate ventures e outsourcing.
}

disso, é essencial compreender a interdependência da ciência em relação a outras áreas da atuação do Estado, como a econômica, política, diplomática e comercial, não somente no âmbito interno, mas também no externo.

$\mathrm{O}$ artigo se inicia com a apresentação do conceito de políticas públicas e das especificidades das políticas de C\&T e de cooperação internacional em C\&T. Em seguida, será ressaltada a importância do Estado como o principal ator que articula e apoia PCIC\&T, tendo em vista sua atuação nacional e regional, sua relação com os outros atores relevantes no campo de C\&T e os desafios que enfrenta atualmente. Por fim, o campo de Análise de Política - e em parte as teorias de Relações Internacionais - oferecerá a base teórica para identificar abordagens adequadas para analisar as PCIC\&T, com o objetivo de contribuir para futuros estudos destas políticas.

\section{Colaboração Internacional em C\&T: Conceito e Atores}

A colaboração internacional em ciência e tecnologia (C\&T) é um tema que vem ganhando espaço nas agendas de diversas nações e instituições internacionais. Hoje, o interesse de estudiosos e tomadores de decisões pelo processo político das colaborações internacionais se intensificou consideravelmente, tendo consequências evidentes nas políticas de cooperação internacional. Este trabalho pretende contribuir para um entendimento mais profundo do tema, seu conceito, contexto e implicações para a C\&T e para as relações políticas nacionais e internacionais.

Inicialmente, pretende-se esclarecer alguns conceitos fundamentais essenciais para compreender a discussão sobre análise de políticas de cooperação internacional em C\&T (PCIC\&T). Em primeiro lugar, políticas são séries de decisões inter-relacionadas que dizem respeito a objetivos, bem como os meios pelos quais estes são atingidos no âmbito de uma situação específica (Jenkins, 1978 apud Ham e Hill, 1993). Elas são posições tomadas por indivíduos ou instituições que contribuem para o contexto no qual sucessivas decisões serão tomadas no futuro (Friend, Power e Yewlett, 1974). São resultado de um processo político e não são expressas em decisões únicas, mas em uma série de deliberações que mudam com o tempo, sendo então seu processo altamente dinâmico (Ham e Hill, 1993). Apesar de suas definições parecerem complexas e muitas vezes vagas, quando se lida com políticas, é relativamente fácil reconhecê-las.

Em relação às políticas públicas, seu conceito foi e é extensamente estudado na academia e o termo possui 
diversas definições, de simples a altamente complexas. O debate acerca de sua definição provou ser vazio, desviando a atenção para discussões improdutivas que afastavam os pesquisadores do estudo real das políticas públicas (Dye, 1992). Deste modo, neste trabalho, política pública é considerada tudo aquilo que os governos escolhem fazer (Dye, 1992), ou seja, uma tomada de posição do Estado com a pretensão de resolver uma questão (Oszlak e O'Donnell, 1995). As respostas geradas permitem que a sociedade infira qual é a posição que está sendo tomada frente a uma determinada questão e interfira caso seja necessário. É preciso acrescentar que, segundo os teóricos políticos, tanto a ação quanto a inação do Estado constituem tomadas de posição e, portanto, políticas públicas (Dye, 1992). As ações ou omissões do Estado interferem em questões de interesse do próprio Estado, mas também de outros atores da sociedade civil: daí deriva a importância do estudo das políticas públicas.

As PCIC\&T fazem parte da Política Científica e Tecnológica (PCT) de uma nação que possui especificidades importantes que devem ser destacadas. Em primeiro lugar, a PCT de fato representa duas políticas: a científica e a tecnológica. A literatura de Estudos Sociais da Ciência e da Tecnologia costuma tratar ambas juntas, pois atualmente a ciência se torna cada vez mais tecnológica e a tecnologia, por sua vez, tem seu aspecto científico aflorado (Dias, 2011). A fronteira entre as duas políticas é de difícil identificação, assim os teóricos optam por tratá-las conjuntamente. Em segundo lugar, no Brasil (e na maioria das nações), as ações públicas para a área de C\&T são tratadas de forma integrada, consistindo no que se chama de Política Nacional de Ciência e Tecnologia (Dias, 2011), descrita em documentos oficiais do governo ${ }^{2}$.

A PCT pode ser definida como o "[...] conjunto de leis, regras, práticas e orientações sob as quais a pesquisa é conduzida [...]" (Dias, 2011: 324). Ela representa o conjunto de medidas públicas que apoiam atividades no âmbito científico e tecnológico e que exploram seus resultados de acordo com os objetivos nacionais (Salomon, 1970). O principal e mais expressivo ator envolvido no desenho e execução da PCT é a comunidade de pesquisa, responsável não somente pela tomada de decisão, mas também pela condução das atividades reguladas pela política. É importante destacar também, no âmbito da C\&T, a atuação do Estado, suas agências e órgãos, que regulam os projetos e programas científicos e

\footnotetext{
A Estratégia Nacional de Ciência, Tecnologia e Inovação 2012-2015 é o documento que aborda as diretrizes e ações para CT\&I no Brasil na atualidade.
}

tecnológicos, bem como os financiam e os mantêm ativos.

A singularidade da PCT em relação a outras políticas públicas se torna evidente a partir do estudo aprofundado de suas características. Em primeiro lugar, ela constitui um objeto de estudo consideravelmente complexo, pois seu escopo envolve diversos temas. Financiamento de programas de pesquisa, recursos e atuação de Instituições de Pesquisa e de Ensino Superior, incentivos à inovação tecnológica e à difusão do conhecimento são alguns poucos exemplos da série de temas que dizem respeito à PCT. Além disso, a PCT constitui um suporte para outras políticas públicas como as de saúde, educação, industrial (Dias, 2011) e até mesmo externa. Por fim, ela é uma das principais responsáveis pelo desenvolvimento nacional, pois apoia a aquisição de novos conhecimentos, o aprimoramento dos já existentes e a formação de recursos humanos de excelência.

Tendo em vista os conceitos apresentados, é possível compreender de forma mais precisa o que são PCIC\&T: ações explícitas dos governos oficiais (regulamentos, programas, acordos oficiais e memorandos de entendimento, investimentos financeiros, etc.) que têm por objetivo influenciar a intensidade, o conteúdo e a direção das colaborações entre pesquisadores através das fronteiras, sejam estes dos setores público ou privado (Comissão Europeia, 2009a). As PCIC\&T podem ser estabelecidas em âmbito nacional - bilateral ou multilateral - ou transnacional, envolvendo um órgão supranacional ou uma governança específica. Elas são inerentemente de longo prazo, pois as atividades que regulam estão além de representarem um importante componente da política externa.

A história das PCIC\&T mundial é longa e inclui diversas iniciativas, programas e acordos de cooperação. Nas últimas quatro décadas, a importância de grandes instalações de pesquisa colaborativa e organizações cresceu, devido à extensão do modelo da Big Science. A Europa foi um dos principais locus destes programas, com o CERN e a Agência Espacial Europeia sendo os grandes exemplos. Em anos mais recentes, são notáveis a coordenação de esforços de diversas agências nacionais de financiamento à pesquisa $\mathrm{e}$ em paralelo, a formulação de estratégias formais de internacionalização de instituições científicas. No Brasil, o destaque é para o Conselho Nacional de Desenvolvimento Científico e Tecnológico (CNPq) e a Fundação de Apoio à Pesquisa do Estado de São Paulo (FAPESP) que possui mais de 60 acordos de colaboração com instituições no exterior. 
Assim, diversos atores são responsáveis pela definição de estratégias de PCIC\&T. Devido à multiplicidade de interesses em jogo, é possível afirmar que a PCIC\&T é menos um conjunto de medidas bem estruturado e mais uma coleção de medidas individuais tomadas por diferentes atores. Os autores que frequentemente moldam a PCIC\&T são:

- Os governos nacionais;

- Ministérios diretamente responsáveis pela PCT. Em geral são atores chaves no lançamento de políticas;

- Ministérios responsáveis por outras áreas, mas que se utilizam de colaborações em C\&T como instrumentos para atingir suas missões políticas. Eles podem ser, por exemplo, na área de agricultura, energia, meio ambiente, relações exteriores, assistência ao desenvolvimento e saúde;

- Organizações públicas com objetivos de financiar pesquisa e tecnologias, como a FAPESP e o CNPq;

- Organizações de pesquisa multilaterais como a European Space Agency (ESA), EUREKA, International Thermonuclear Experimental Reactor (ITER), Human Frontier Science Program (HFSP);

- Organizações não governamentais, que têm como missão apoiar pesquisa científica;

- Instituições de pesquisa e suas associações, como universidades e centros de pesquisa;

- Embaixadas e representações estrangeiras que oferecem inteligência estratégica em países específicos.

Apesar de perder espaço para outras instituições atualmente ${ }^{3}$, os órgãos do Estado - ministérios ou departamentos responsáveis diretamente por questões de C\&T - ainda são os principais atores quando o assunto são PCIC\&T. A importância estratégica da C\&T no mundo globalizado é cada vez mais reconhecida pelos Estados Nacionais e pela comunidade internacional. Principalmente após o final da Guerra Fria, os Estados utilizam a colaboração internacional mais intensamente, combinando C\&T com economia e geopolítica (Silva, 2007). Atualmente, há um apelo generalizado pelo aumento da cooperação internacional em C\&T, devido ao reconhecimento de que estas atividades avançam o conhecimento, trazem importantes benefícios, poupam custos e são uma

\footnotetext{
O Estado Nacional perde espaço em termos de políticas e estratégias nacionais para diversos outros atores, que irrompem no cenário de C\&T. O panorama político em C\&T está se transformando: a globalização das últimas décadas intensificou a necessidade de desenvolver estas políticas de forma mais estratégica, tornando-as mais efetivas. (Comissão Europeia, 2009a). Porém, a figura do Estado ainda predomina no tema de políticas para cooperação internacional em C\&T.
}

forma de aplicar de forma mais efetiva os resultados dos esforços científicos empreendidos (Katz, 1994). As agências ou organismos financiadores são também bastante ativos e possuem estratégias e programas próprios. São notáveis também iniciativas de outros ministérios ${ }^{4}$ no desenvolvimento e na manutenção de colaborações em C\&T. Assim, ações de colaboração internacional são conduzidas por meio de uma série de estratégias de diferentes tipos de atores, mesmo no âmbito do Estado Nacional.

As atividades de C\&T são elementos essenciais para o desenvolvimento nacional, pois afetam, direta ou indiretamente, diversos aspectos da vida econômica e social. Da mesma forma, o Estado é vital para a concretização de atividades de C\&T, seja por meio de seu apoio político a acordos e parcerias, seja pelo comprometimento e investimento financeiro a projetos e programas. Em termos mais específicos, a cooperação internacional em C\&T gera desenvolvimento científico, pois conta com a assistência do Estado para garantir investimentos e apoio institucional aos cientistas a longo prazo. O Estado é o ator fundamental para viabilizar investimentos públicos ${ }^{5}$ e privados para a construção da estrutura de pesquisa necessária ao desenvolvimento da C\&T, além de prover suporte institucional para que os cientistas assumam responsabilidades em grandes empreendimentos internacionais e defendam seus interesses perante organizações internacionais. Ele é responsável por gerir e promover a cooperação internacional, por meio de políticas públicas implementadas por suas instituições e apoio institucional para o desenvolvimento de atividades colaborativas, desde sua celebração formal na forma de acordos, até o acompanhamento e avaliação dos resultados. O Estado também tem a incumbência de investir na formação de recursos humanos, garantindo apoio financeiro e institucional para a qualificação de cientistas de acordo com as necessidades nacionais e proteger a propriedade intelectual gerada com o desenvolvimento científico e tecnológico (Duarte, 2008).

\section{Os Desafios do Estado em PCIC\&T}

O Estado é um dos principais atores na esfera de C\&T e é vital para as colaborações internacionais em C\&T. Ele torna possível o desenvolvimento científico e

\footnotetext{
${ }^{4}$ Bastante atuantes em diversos países são os relacionados a questões de saúde e agricultura.

5 Diretamente, por meio de suas agências de fomento ou indiretamente por meio do estímulo a iniciativas de integração universidadeempresa e incentivos fiscais ao setor privado.
} 
tecnológico proveniente das atividades de cooperação internacional (Duarte, 2008) pelas razões já vistas: ele é capaz de financiar grandes empreendimentos de longo prazo e incentivar a formação e capacitação de recursos humanos e é o único ator que pode celebrar acordos de cooperação com outros países e defender e representar interesses nacionais em grandes foros mundiais (Duarte, 2008). Desta forma, seu papel perpassa os dos demais atores, pois

Como visto, o Estado é um ator fundamental na formulação, execução e avaliação de políticas voltadas ao estímulo à cooperação internacional em C\&T. Além disso, atualmente, outros atores públicos têm se envolvido cada vez mais na realização destas atividades e têm formulado e implementado importantes políticas e programas colaborativos específicos, atendendo interesses próprios. Na consecução destas atividades, tanto o Estado quanto estes novos atores na esfera da colaboração internacional em C\&T - agências de fomento, instituições de pesquisa, ministérios e outros - enfrentam desafios institucionais, políticos, jurídicos que dificultam o delineamento de estratégias para a cooperação internacional e consequentemente sua avaliação. As organizações de fomento, em particular, ainda lutam com o design e a implementação de estratégias, bem como com a determinação do nível e tipo de envolvimento internacional que desejam. Os próprios formuladores de políticas estão no começo de uma jornada em direção a estratégias de internacionalização mais conscientes e compreensivas (Comissão Europeia, 2009b).

Para os Estados, um dos principais desafios atuais em relação à estratégia de colaboração internacional é o ajuste dos compromissos assumidos às legislações nacionais. Muitas vezes, esta tarefa exige longos acordos diplomáticos, com até mesmo eventuais ajustes no sistema nacional de C\&T (Costa Filho, 2006). Outro desafio é a criação e adoção de uma estratégia nacional para cooperação internacional em C\&T. Segundo o relatório da Comissão Europeia (2009a, b) sobre cooperação internacional que analisou colaborações de países europeus e de outros continentes, nenhum país examinado possui uma estratégia coerente e coordenada para cooperação internacional e têm atores organizados de forma explícita. A direção geográfica da cooperação (e outros aspectos desta) é feita de forma $a d h o c$, caso a caso, em geral se pautando pelos benefícios científicos esperados, por razões políticas e diplomáticas e de acesso a mercados, por ganhos em mobilidade e por aspectos de reputação e laços históricos, linguísticos e culturais. As prioridades temáticas são estabelecidas de forma implícita ou ex post, ou seja, após a definição dos parceiros e do modo como a atividade será conduzida. Em casos raros há estratégias para disciplinas científicas específicas. Em geral, elas estão baseadas em objetivos amplos e globais, em atividades horizontais e focadas em determinados países (Comissão Europeia, 2009b).

Além disso, não há coordenação suficiente dos programas pelos parceiros participantes, por falta de conjugação de esforços, comprometendo a eficiência destes. A atuação internacional, apesar de ser uma preocupação política há muitos anos, somente recentemente ganhou a atenção dos legisladores como uma dimensão política de C\&T que engloba diversas atividades e pode ser explorada de forma mais estratégica. Tendo em vista que a maioria dos países reconhece que a cooperação em $C \& T$ representa não somente uma estratégia de ascensão científica e tecnológica, mas também um meio para atingir outras finalidades políticas, econômicas, diplomáticas, as atividades cooperativas seriam ferramentas políticas mais poderosas se

\section{Campo de Análise de Política}

Considerando a importância cada vez maior do Estado como articulador de iniciativas no campo internacional da C\&T, elaborando políticas e estratégias que procuram atingir objetivos nacionais, surgem questões a respeito de como estas políticas podem ser analisadas, medindo resultados e considerando impactos - outro desafio importante que este ator enfrenta atualmente. Neste sentido, o campo de Análise de Políticas apresenta elementos teóricos importantes que serão considerados neste trabalho.

O interesse pela análise de políticas públicas surgiu nos Estados Unidos nos anos 60 quando a sociedade passou a reconhecer o quanto era complexo enfrentar os desafios que se impunham ao governo; os acadêmicos introduziram este tema no rol de seus interesses, avançando o conhecimento sobre este assunto; e os tomadores de decisão iniciaram discussões sobre formas de solucionar problemas. O interesse pela análise de políticas cresceu bastante nos últimos anos (Ham e Hill, 1993).

A Análise de Política é uma abordagem multidisciplinar que envolve conhecimentos, conceitos, teorias e ideias de diversas disciplinas como economia, psicologia, sociologia, relações internacionais entre outras. Segundo Dye (1976 apud Ham e Hill, 1993) análise de política é um processo de descoberta, por meio do qual é possível identificar o que os governos fazem, o porquê destas ações e que resultados elas trazem, ou seja, é uma descrição e explicação das causas e consequências da ação do governo. A Análise de Políticas assiste os tomadores 
de decisão a aprimorar a qualidade das políticas públicas e da informação disponível e a orientar suas decisões, desenvolvendo conhecimento sobre o processo politico.

Como as políticas públicas possuem diversas dimensões (resultados, impactos, processos, etc), Young (1977 apud Ham e Hill, 1993) aponta sete tipos mais comuns de estudos para a Análise de Políticas. Primeiramente, há trabalhos que se focam no conteúdo das politicas, nos quais são descritos e explicados a gênese e o desenvolvimento de determinadas políticas. Em segundo lugar, existem estudos do processo político, ou seja, investigações acerca das etapas pelas quais as questões passam no processo político e sobre os fatores que as afetam. Em terceiro lugar, é possível citar os estudos dos resultados das políticas, que pretendem compreender as políticas em termos de seu impacto e contribuição para os âmbitos social, econômico, tecnológico e outros. Existem também os estudos de avalição e os estudos informativos para os tomadores de decisão. Os primeiros são puramente avaliativos e os segundos se utilizam de dados para auxiliar os tomadores de decisões a deliberar. Por fim, os estudos de process advocacy têm o objetivo de aprimorar o processo político, contribuindo para realocar funções e tarefas, planejar sistemas e apresentar novas abordagens de avaliação de opções; e o policy advocacy que envolvem atividades nas quais o analista exerce pressão pela adoção de determinadas opções de política e ideias no processo político (Dye, 1992).

Os estudos de avaliação marcam uma divisão importante no campo de Análise de Política. Eles separam a chamada análise de política (analysis of policy) que se propõe a compreender mais profundamente as políticas e seu processo da chamada análise para política (analysis for policy) que prescreve ações para aprimorá-la (Dye, 1992). Assim, é possível analisar políticas públicas de diferentes maneiras, dependendo da dimensão que o analista escolhe para pousar seu foco.

Além do foco, o analista também deverá optar por um modelo de análise de política. Os principais modelos descritos na literatura não foram desenhados especificamente para o estudo das políticas públicas (Dye, 1992), mas advêm de outras áreas do conhecimento, o que acaba enriquecendo a análise. Estes modelos se propõem a simplificar a realidade e esclarecer alguns aspectos importantes dos problemas que os tomadores de decisão e a sociedade enfrentam.

Apesar de não terem sido criados com o objetivo de analisar PCIC\&T, os modelos que serão apresentados neste estudo ${ }^{6}$ possuem elementos importantes para o estudo destas politicas e daqueles que estão envolvidos

${ }^{6}$ Embasados na obra de Dye (1992). em seu processo de formulação e implantação. Os modelos de análise de política selecionados são aqueles que apresentam potencial para contribuir especificamente para o estudo das PCIC\&T, levando em conta as especificidades apresentadas anteriormente. No âmbito das PCIC\&T, a análise de política possui duas dimensões importantes: a nacional, na qual se observa a atuação do Estado nacional, formulando e executando políticas e se relacionando com outros atores da nação, bem como com instituições e governos no exterior; e a dimensão transnacional, na qual o Estado nacional auxilia na formulação de regras de organizações supranacionais de C\&T, que acabam influenciando regulamentos nacionais e regionais. É importante notar que, pelo fato de envolver atores e interesses internacionais, as PCIC\&T também podem ser estudadas à luz das teorias de Relações Internacionais, que contribuem com conceitos e perspectivas interessantes.

A apresentação dos principais modelos da Análise de Política não pretende julgar a primazia de certos modelos sobre outros. O campo de Análise de Política, como visto, é uma área multidisciplinar que utiliza conhecimentos e conceitos de outras áreas do conhecimento para compreender o processo e o sistema político. Os modelos apresentados, derivados destas diversas áreas, não pretendem ser concorrentes, mas contribuir conjuntamente para uma análise aprimorada. Com o objetivo de obter um diagnóstico preciso das políticas, os modelos ordenam e simplificam a realidade, identificando aspectos relevantes das políticas públicas e dos fenômenos, a elas relacionados, que podem ser observados, medidos e verificados. Os modelos apresentam referencial empírico e transmitem informações significativas, ou seja, explicações das causas e consequências das políticas públicas (Dye, 1992).

\section{Os Modelos de Análise de Política e sua Aplicação em PCIC\&T}

O modelo institucional analisa políticas públicas tendo em vista a importância das instituições em todas as etapas do processo político. Em primeiro lugar, uma política não é considerada pública ao menos que seja adotada, aplicada ou implementada por alguma instituição do governo. Assim, a abordagem se concentra na descrição de instituições governamentais específicas, suas estruturas, organização, tarefas e funções.

A importância das instituições para o processo político advém de pelo menos três fatores que também influenciam os cidadãos na luta por seus interesses junto ao Estado: a legitimidade, que é conferida pelas instituições às politicas que, por isso, se transformam 
em obrigações legais que comandam a lealdade dos cidadãos; a universalidade, que representa a extensão das políticas a todos na sociedade; e a coerção, monopólio legítimo do uso da força utilizado pelo governo quando há transgressão das políticas estabelecidas (Dye, 1992).

As instituições possuem padrões estruturados de comportamento que persistem no tempo e afetam o conteúdo das políticas que formulam e implementam. Além disso, a forma como estas instituições se organizam pode priorizar interesses e atores, dando a estes mais acesso a estruturas de decisão, afetando, assim, as dimensões nas quais a política atua.

Considerando o modelo institucional, em relação à perspectiva nacional das $\mathrm{PCIC} \& \mathrm{~T}^{7}$, elas são formuladas e executadas por instituições do governo ou ligados a ele, como os ministérios e outros órgãos. Um dos principais atores atualmente são as agências de fomento que, pelo fato de terem uma posição privilegiada na dinâmica científica, provendo financiamento à pesquisa, não somente formulam políticas próprias, mas também influenciam políticas nacionais, bem como os hábitos da comunidade de pesquisa - que acaba escolhendo temas de trabalho ou países parceiros de acordo com as oportunidades oferecidas por estas agências. No âmbito transnacional, a PCIC\&T se apresenta na forma de grandes projetos da Big Science e instituições autônomas de pesquisa como o Conseil Européen de Recherche Nucléaire (CERN). Estes programas são coordenados por cientistas de vários países e apesar de serem financiados por Estados, têm autonomia para definir sua agenda de pesquisa e o direcionamento de seus gastos.

Esta abordagem encontra paralelo na teoria neoliberal institucionalista das Relações Internacionais cujo foco de análise é a interdependência, a cooperação internacional e as condições nas quais a ação coletiva ocorre. Em uma análise das PCIC\&T tendo em vista a atuação dos Estados no âmbito transnacional, a perspectiva pode elucidar como as instituições internacionais assistem os Estados na consecução de objetivos que envolvem ação coletiva ${ }^{8}$.

A perspectiva institucionalista se torna cada vez mais relevante para a análise das PCIC\&T tendo em vista a importância crescente das instituições internacionais de pesquisa. Atualmente, reconhece-se

\footnotetext{
Nota-se que a perspectiva nacional abarca as relações entre o Estado nacional e os atores nacionais (como a comunidade de pesquisa, os centros de pesquisa, a sociedade local, etc.), bem como os atores internacionais, incluindo governos estrangeiros, comunidades de pesquisa internacionais, agências de fomento de outros países, entre outros

${ }^{8}$ Para uma compreensão aprofundada, consultar Keohane (1984).
}

a fundamental contribuição destas para o avanço da ciência ${ }^{9}$ e para o aumento das colaborações internacionais. É crescente também a atuação do Estado e de suas agências - com particular destaque para as agências de fomento - na criação de oportunidades, execução e manutenção de colaborações internacionais por meio de PCIC\&T. A forma como estas instituições atuam afeta não somente a comunidade de pesquisa, mas a sociedade como um todo, por isso é fundamental, para uma análise efetiva, compreender como estes atores interagem no sistema político e como os últimos influenciam os primeiros.

A perspectiva da teoria dos grupos considera como fato central da politica a interação entre grupos políticos ${ }^{10}$ que são formados, de modo formal ou informal, por indivíduos com interesses semelhantes que reivindicam demandas junto a instituições do governo. Assim, estes teóricos consideram a relevância dos indivíduos somente como parte e voz de interesses de grupos. Os tomadores de decisão respondem a pressões de grupo, negociando e se comprometendo com demandas de diversos grupos políticos. A política, nesta concepção, representa a luta entre diversos grupos com o objetivo de influenciar as políticas públicas, formuladas quando o equilíbrio entre eles é estabelecido, determinado pela relativa influência de cada grupo ${ }^{11}$. Quando há mudanças nestas influências, as políticas públicas também sofrem transformações. O sistema politico é responsável por gerir o conflito entre os grupos, estabelecendo as regras do jogo, equilibrando interesses e reforçando compromissos.

Com relação à análise das $\mathrm{PCIC \& T}$, a teoria do grupo considera a existência de diversos grupos de pressão influenciando as decisões do governo nacional e suas agências. Um dos grupos de maior influência é a comunidade de pesquisa nacional, que engloba cientistas de diversas áreas do conhecimento. Além destes, atuam também as comunidades de pesquisa e instituições de fomento internacionais, organizações internacionais de pesquisa e grupos de assistência à pesquisa no exterior (aqueles envolvidos com research-for-aid). Pelo fato de a colaboração internacional em C\&T envolver dimensões não científicas, como a econômica, política e social, outros grupos fora da esfera da C\&T também se apresentam como concorrentes importantes nos âmbitos nacional e internacional. Um exemplo

\footnotetext{
9 A recente descoberta do Bóson de Higgs somente foi possível devido à utilização do acelerador de partículas do CERN, cujos projetos envolvem expertise de diversas nações.

${ }^{10}$ Partidos políticos são exemplos importantes de grupos.

${ }^{11}$ Esta influência depende de diversos fatores como o número de membros, a riqueza, a força organizacional e coesão interna.
} 
bastante ilustrativo é a influência das políticas externa e econômica e seus atores no campo das PCIC\&T. Grupos que representam interesses exportadores ou de certos setores da diplomacia podem influenciar a constituição de acordos em C\&T com o objetivo de aproximar duas nações. Esta aproximação desenvolve vínculos e parcerias, cria laços de confiança, respeito e credibilidade e abre espaço para negociações em outras dimensões da atividade estatal. Os tomadores de decisão em PCIC\&T estão sujeitos às pressões de todos estes grupos cuja disputa produz políticas públicas que definem a agenda de pesquisa dos programas em parceria, o valor dos investimentos destinados a projetos e até mesmo os países parceiros.

Novamente para esta abordagem, o campo de Relações Internacionais apresenta contribuições importantes, avançando a análise das ações e comportamentos dos estados que afetam ou criam novas PCIC\&T. Os regimes internacionais ${ }^{12}$ são exemplos de grupos formados por diferentes nações com interesses e objetivos comuns. Estes arranjos internacionais constituem em sua essência leis e normas gerais que afetam os diversos Estados. Estes regimes concorrem com instituições internacionais supranacionais que versam sobre o mesmo tema, bem como com outros regimes, instituições regionais e até mesmo decisões políticas nacionais. De todos estes fatores advém a importância de habilidades de barganha, negociação e comprometimento destes grupos na busca por seus interesses. Desta forma, regimes internacionais representam importantes grupos de pressão no cenário de formulação e negociação de PCIC\&T.

A Teoria da Elite percebe as políticas públicas como desenhadas de acordo com as preferências e valores de um grupo, uma elite, que detém o poder. Este grupo é formado por membros que compartilham valores fundamentais sobre o sistema social e sobre a preservação e estabilidade deste, ou seja, há um consenso sobre as regras do jogo. As políticas não refletem as demandas das massas - que são indiferentes e mal informadas em assuntos relacionados à política - mas estão de acordo com os valores da elite. Os legisladores e administradores também possuem um papel marginal, pois somente executam políticas que foram definidas previamente pela elite. Neste sentido, as políticas possuem caráter mais incremental do que revolucionário e as mudanças que ocorrem representam, na verdade, uma redefinição de valores da própria elite, sempre com o objetivo de preservar o sistema e manter seu poder.

\footnotetext{
${ }^{12}$ Conceito criado por Stephen Krasner (1982) para classificar os "princípios, normas, regras e processos de tomadas de decisão, implícitos ou explícitos para os quais convergem as expectativas dos atores em determinada área das relações internacionais" (Krasner, 1982: 2. Tradução nossa).
}

Considerando o contexto das PCIC\&T, a teoria da elite é uma das abordagens que oferece mais elementos interessantes para sua análise. No âmbito estatal, é possível identificar, nos diferentes países, uma elite que predomina nos debates sobre C\&T. No caso brasileiro e no de muitos outros países, é a comunidade de pesquisa que exerce papel preponderante. Neste caso, as políticas voltadas para cooperação internacional estabelecidas pelo governo nacional recebem muita influência deste grupo que acaba moldando as ações do Estado em detrimento da participação de outros grupos, como Organizações Não-Governamentais (ONGs), movimentos sociais e outros. Em questões de C\&T, há diversas discussões acerca da participação da comunidade no processo político, justamente pelo fato de os grupos dominantes atestarem o desconhecimento e falta de preparação de outros grupos em assuntos relacionados à ciência.

No âmbito do sistema internacional de relações de cooperação entre os Estados, é possível identificar um grupo dominante, a elite da comunidade internacional, representada pelas nações do norte ${ }^{13}$. Estas são responsáveis por cerca de $95 \%$ da pesquisa e desenvolvimento (P\&D) mundiais (Kerwin, 1981). As parcerias entre estes países são frequentemente estruturadas e apoiadas financeiramente por recursos do norte e se concentram em universidades e institutos públicos de pesquisa de nações do sul (Baud, 2001). Apesar de amplos e contínuos esforços, a cooperação norte-sul continua sendo entre parceiros desiguais, ou seja, há uma dominância dos parceiros do norte, que financiam as pesquisa, definem a agenda e acabam coordenando todo o processo. Assim, é possível afirmar que a teoria da dependência é tão válida para o desenvolvimento econômico quanto para a C\&T.

A teoria dos jogos é o estudo das decisões racionais de dois ou mais atores em situações nas quais estes tomam decisões e o resultado desta interação depende das escolhas feitas por todos eles. As decisões dos atores são interdependentes, pois as ações tomadas refletem não somente os anseios de um jogador, mas também suas expectativas em relação às dos outros.

A análise de políticas por meio da teoria dos jogos deriva da teoria da escolha racional e os elementos que a abordagem oferece têm como ponto de partida a observação de diversas opções - levando em consideração as ações dos outros jogadores - em situações competitivas e estratégicas. Assim, o modelo apresenta as regras do jogo, ou seja, as escolhas disponíveis aos jogadores e os payoffs,

\footnotetext{
${ }^{13}$ Segundo Hassan (2010) há cerca de 25 países no mundo com capacidades fortes em CT\&I, a maioria deles membros da OCDE. Nações com capacidade moderada em CT\&I são em torno de 100 e incluem países do mundo em desenvolvimento; e 77 nações, em sua maioria países subsaarianos e do mundo islâmico, possuem fraca capacidade em CT\&I.
} 
ou os valores que cada jogador atribui às diversas opções, considerando suas escolhas e aquelas de seus oponentes.

Considerada mais como uma ferramenta analítica do que um modelo completo de análise de políticas públicas e uma combinação de matemática e lógica (Folker, 2005), a teoria dos jogos se apresenta interessante para a análise das PCIC\&T (assim como para as Relações Internacionais) por se concentrar principalmente no processo de tomada de decisão e por conferir importância à interação entre os atores. Ela é muito utilizada no campo de Relações Internacionais para analisar ações tomadas pelos Estados tanto em situações de conflito quanto de cooperação.

Para analisar a PCIC\&T à luz da teoria dos jogos é preciso primeiramente compreender que a cooperação, apesar de ser algo positivo e que traz benefícios aos envolvidos, implica também em conflitos e competição ${ }^{14}$ (Folker, 2005). Uma relação de colaboração representa um jogo que pode ser chamado de "cooperativo" ou "não cooperativo". Nos primeiros, os payoffs são positivos, ou seja, todos os jogadores ganham ${ }^{15}$. Nos segundos, chamados também de soma zero, há ganhadores e perdedores e os pay offs - ou seja, os valores de ganhos ou perdas que o analista atribuiu para cada ação quando esta é selecionada - quando somados, resultam em zero, ou seja, os ganhos obtidos por um jogador são as perdas equivalentes de outro jogador (Folker, 2005).

No âmbito das PCIC\&T, os jogos cooperativos, nos quais há somente payoffs positivos, são representados por programas conjuntos de desenvolvimento de projetos, como o Projeto Genoma, que criou um grande fluxo de troca de informações entre as nações e contribuiu - também no caso do Brasil - para a solução de problemas locais. Já os jogos de soma zero ocorrem, por exemplo, quando políticas voltadas à atração de pesquisadores a países desenvolvidos acarretam em fuga de cérebros de países do sul que, muitas vezes, não oferecem condições tão favoráveis aos cientistas quanto os países do norte.

A teoria da escolha pública faz parte de uma gama de estudos advindos do campo da Economia que se preocupa com decisões dos diversos atores fora do mercado. Segundo estes teóricos, os indivíduos atuam na política da mesma forma como no mercado: procuram maximizar seus benefícios pessoais

\footnotetext{
${ }^{14}$ Podem-se imaginar conflitos para obter financiamento desejado para determinado projeto conjunto; resguardar determinada tecnologia de cair nas mãos de possíveis concorrentes; ou evitar fuga de cérebros. Situações de competição podem ocorrer, por exemplo, quando se deseja chegar a uma descoberta antes do parceiro ou conquistar acesso à biodiversidade de uma determinada região no estrangeiro.

${ }^{15}$ Isso não significa que os ganhos são semelhantes ou iguais. É possível que um jogador tenha benefícios bem maiores do que o outro.
}

(self-interest). A política é somente um meio pelo qual estes atores aumentam seu bem-estar, sendo não proposital a geração de benefícios a outros indivíduos. Assim, a ação coletiva é incentivada pelo desejo de maximizar bem-estar próprio.

Grande parte destes estudos se concentra na responsabilidade do Estado em prover bens públicos ${ }^{16}$ aos seus cidadãos, que lutam constantemente por seu bem-estar. O conhecimento científico e tecnológico pode ser considerado um bem público, assim como a justiça e a segurança. No contexto de colaboração internacional para geração e intercâmbio de conhecimento em C\&T, os diversos atores envolvidos possuem objetivos particulares ${ }^{17} \mathrm{e}$ procuram maximizar seu próprio bem-estar ${ }^{18}$. Segundo os estudiosos da escolha pública, quando os Estados se articulam de diversas formas para buscar interesses próprios, eles acabam beneficiando outros atores. Regimes internacionais da área ambiental são exemplos interessantes, pois nem todas as nações participam destes e cumprem com as decisões tomadas. No entanto, todas elas se obtêm benefícios (como a redução da poluição global, por exemplo) ocasionados pelo comprometimento de alguns países com as metas estabelecidas. Outro exemplo interessante são tecnologias desenvolvidas com o apoio do Estado para fins militares que, após sofrerem algumas adaptações, acabaram melhorando a vida de civis ${ }^{19}$. Neste caso, o interesse próprio do Estado em se proteger de inimigos externos (motivação egoísta) acabou por beneficiar uma parcela de cidadãos que puderam usufruir destas tecnologias no seu dia-a-dia.

O Quadro 1 resume os modelos de análise de politica abordados, apresentando suas principais características. Além disso, o quadro apresenta as contribuições dos modelos para a análise das PCIC\&T tanto da perspectiva nacional quanto da transnacional, bem como o subsídio concedido à análise pela Teoria das Relações Internacionais.

\footnotetext{
${ }^{16} \mathrm{O}$ conceito de bem público advém da Economia e classifica aqueles bens não exclusivos - ou seja, estão disponíveis a todos os cidadãos - e não rivais, aqueles bens cujo consumo por um individuo não impede seu consumo por outro.

${ }^{17}$ A comunidade de pesquisa, por exemplo, procura espaço para poder decidir sobre temas de pesquisa de seu interesse e luta por mais financiamento. O Estado Nacional tem interesse na formação de recursos humanos de qualidade, atração de investimentos estrangeiros e obtenção de financiamento para condução de pesquisa que seja relevante localmente. No sistema internacional ele procura proteger sua comunidade de pesquisa, seus conhecimentos e suas tecnologias além de trabalhar para garantir seu prestígio junto à comunidade internacional, visando poder de barganha também em outras áreas fora da C\&T

${ }^{18}$ Contribui para este bem-estar o cumprimento de normas por outros atores com os quais o Estado lida.

19 É possível citar tecnologias de blindagem de veículos, de comunicação, entre outras.
} 
Quadro 1. Resumo das Abordagens.

\begin{tabular}{|c|c|c|c|c|}
\hline \multirow{2}{*}{$\begin{array}{c}\text { Modelo de análise } \\
\text { de política }\end{array}$} & \multirow{2}{*}{ Características } & \multicolumn{2}{|c|}{ Contribuição para análise de PCIC\&T } & \multirow{2}{*}{$\begin{array}{c}\text { Contribuição da } \\
\text { Teoria das Relações } \\
\text { Internacionais }\end{array}$} \\
\hline & & Nacional & Transnacional & \\
\hline Institucionalismo & $\begin{array}{l}\text { Essencialidade das } \\
\text { instituições no processo } \\
\text { político; } \\
\text { Descrição, estruturas, } \\
\text { organização, tarefas e } \\
\text { funções. }\end{array}$ & $\begin{array}{l}\text { Maior atenção do } \\
\text { governo aos temas de } \\
\text { C\&T; } \\
\text { Destaque para as } \\
\text { agências de fomento. }\end{array}$ & $\begin{array}{l}\text { Projetos da } \\
\text { Big Science } \\
\text { e instituições } \\
\text { autônomas. }\end{array}$ & $\begin{array}{l}\text { Neoliberalismo } \\
\text { Institucional }\end{array}$ \\
\hline Teoria dos Grupos & $\begin{array}{l}\text { Grupos de pressão como } \\
\text { foco de análise; } \\
\text { Política está baseada na luta } \\
\text { pelo poder entre diferentes } \\
\text { grupos. }\end{array}$ & $\begin{array}{l}\text { Comunidade de } \\
\text { pesquisa como maior } \\
\text { grupo de pressão; } \\
\text { Concorrem também } \\
\text { grupos econômicos e } \\
\text { políticos. }\end{array}$ & $\begin{array}{l}\text { Grupos } \\
\text { internacionais e } \\
\text { transnacionais. }\end{array}$ & Regimes Internacionais \\
\hline Teoria das elites & $\begin{array}{l}\text { Politicas públicas são } \\
\text { desenhadas de acordo com } \\
\text { as preferências de uma elite. }\end{array}$ & $\begin{array}{l}\text { Comunidade de } \\
\text { pesquisa exerce papel } \\
\text { preponderante. }\end{array}$ & $\begin{array}{l}\text { Nações de } \\
\text { excelência } \\
\text { científica - as } \\
\text { nações do norte. }\end{array}$ & Teoria da dependência \\
\hline Teoria dos jogos & $\begin{array}{l}\text { Decisões cujos resultados } \\
\text { dependem das escolhas de } \\
\text { todos os atores. }\end{array}$ & $\begin{array}{l}\text { Jogos cooperativos ou } \\
\text { não cooperativos. }\end{array}$ & $\begin{array}{l}\text { Jogos } \\
\text { cooperativos ou } \\
\text { não cooperativos } \\
\text { (fuga de } \\
\text { cérebros). }\end{array}$ & Teoria dos Jogos \\
\hline Escolha Pública & $\begin{array}{l}\text { Ação coletiva é motivada } \\
\text { pelo desejo de maximização } \\
\text { de benefícios próprios. }\end{array}$ & $\begin{array}{l}\text { Atores nacionais } \\
\text { buscam interesses } \\
\text { próprios. }\end{array}$ & $\begin{array}{l}\text { Estados } \\
\text { representam } \\
\text { interesses } \\
\text { nacionais } \\
\text { no sistema } \\
\text { internacional. }\end{array}$ & Regimes Internacionais \\
\hline
\end{tabular}

Fonte: Elaboração própria.

\section{Conclusão}

Como conclusão, é crucial ressaltar novamente a importância das especificidades da PCT e da PCIC\&T para uma análise completa das mesmas e da atuação da comunidade de pesquisa e do Estado no desenvolvimento de ambas. No contexto das PCIC\&T, como visto, o Estado se apresenta como ator preponderante, responsável por diversas etapas pelas quais estas políticas passam no processo político e até mesmo no sistema internacional. Atualmente, devido principalmente à importância conferida ao tema, as dificuldades pelas quais os Estados passam na formulação, execução e avaliação de PCIC\&T acabam sendo evidenciadas. Com o intuito de contribuir para um maior entendimento sobre estas políticas e sobre como o Estado lida com elas, este estudo buscou ressaltar os pontos positivos de algumas abordagens de análise destas políticas advindas do campo de Análise de Políticas.

O campo de Análise de Política oferece abordagens interessantes para a condução de análises de PCIC\&T.
Este estudo se concentrou em algumas delas, em especial, aquelas que possuem o maior número de elementos relevantes para o estudo das PCIC\&T, considerando as especificidades apresentadas anteriormente ${ }^{20}$. Devido a estas singularidades, mas em especial ao fato destas políticas abrangerem a dimensão internacional, as teorias de Relações Internacionais oferecem um suporte teórico importante de análise, trazendo também contribuições relevantes para o campo da Análise de Política ${ }^{21}$. Os diversos modelos aqui apresentados - advindos da Análise de Política - não pretendem concorrer entre si, pois não há um modelo ótimo a ser aplicado a uma determinada

\footnotetext{
${ }^{20}$ Principalmente em relação ao fato destas políticas fazerem parte da PCT nacional e de envolverem a participação de atores internacionais no processo decisório, implementação e avaliação das mesmas.

${ }^{21}$ As teorias de Relações Internacionais oferecem amplo apoio em análises de regimes internacionais e organizações internacionais de pesquisa, mas é importante notar também que no âmbito das PCIC\&T do Estado Nacional, interesses estrangeiros estão em jogo e concorrem com interesses domésticos.
} 
avaliação de políticas. É responsabilidade do analista determinar quais abordagens se adequam melhor às políticas em questão. Uma análise verdadeiramente eficaz é aquela que combina conceitos de diversos modelos, pois são evidentes, por exemplo, tanto as contradições norte-sul, os interesses conflitantes dos parceiros quanto à importância das instituições e a dominação de certos grupos na tomada de decisão, perspectivas adotadas por vários dentre os modelos apresentados.

Por fim, é crucial observar os limites de cada uma destas abordagens e considerá-los quando da escolha da melhor alternativa para a análise. Um analista que procura compreender as relações entre a estrutura das instituições do governo e o conteúdo da política pública encontrará dificuldades se adotar uma abordagem institucionalista. Também poderá encontrá-las, caso deseje estudar organizações de assistência à pesquisa internacional (focada no research-for-aid), adotando a teoria da escolha pública. O uso da teoria dos jogos na análise de políticas se apresenta como uma tarefa árdua, pois o conhecimento sobre os verdadeiros payoffs atribuídos pelos jogadores e suas possíveis escolhas de ação não é perfeito, dificultando a tomada de decisão. Quanto às teorias de elite e grupo, é preciso primeiramente investigar a ação de grupos latentes, ou seja, aqueles que em geral não estão visíveis à sociedade, mas que podem influenciar as decisões de outros atores no processo político, pois estes indivíduos podem acabar transformando as regras do jogo, formando novas coalizões.

Assim, espera-se, com este estudo, elucidar as diversas ferramentas de análise disponíveis para as PCIC\&T - em essência, aquelas mais adequadas a esta tarefa - e inspirar trabalhos neste campo, devido não somente à importância atribuída ao tema nas últimas décadas, mas também à falta de estudos deste tipo - cuja principal consequência é a persistência de desafios impostos aos atores envolvidos com PCIC\&T que somente serão solucionados caso haja maior conhecimento sobre seu processo.

\section{Referências}

Baud, Isa. 2001. North-South Partnerships in Development Research: An Institutions Approach. In J. Bouma (org.), North-South Research Cooperation. Amsterdam: Royal Netherlands Academy of Arts and Sciences, p. 51.

Brasil. Ministério de Ciência, Tecnologia e Inovação - MCTI. 2002. Livro Branco: Ciência, Tecnologia e Inovação. Brasília: Ministério de Ciência, Tecnologia e Inovação.
Comissão Europeia. 2009a. Drivers of International collaboration in research. Final Report. Luxembourg: Publications Office of the European Union.

Comissão Europeia. 2009b. Drivers of International collaboration in research. Anexo 1. Luxembourg: Publications Office of the European Union.

Costa Filho, Edmilson. 2006. A dinâmica da cooperação espacial sul-sul: o caso do programa CBERS. Tese de doutorado, Universidade Estadual de Campinas.

Dias, Rafael. 2011. O que é a política científica e tecnológica? Sociologias, 13(18): 316-344.

Duarte, Rafael. 2008. Cooperação Internacional para o Desenvolvimento em Ciência e Tecnologia: A Participação Brasileira na Organização Européia para Pesquisa Nuclear (CERN). Journal Of Technology Management And Innovation, 4(3): 133-151.

Dye, Thomas. 1992. Understanding public policy. Londres: Prentice-Hall. PMCid:PMC2328749.

Folker, Jennifer. 2005. Making sense of International Relations Theory. Colorado: Lynne Rienner Publishers. PMCid:PMC1266433.

Friend, John Kimball; Power, John Marcus e Yewlett, Chris. 1974. Public Planning: The Inter Corporate Dimension. Londres: Tavistock.

Ham, Christopher e Hill, Michael. 1993. The policy process in the modern capitalist state. Londres: Harvester Wheatsheaf.

Hassan, Mohamed. 2010. Global Challenges and opportunities for international cooperation in science and technology. In T. Pires (ed.), Cooperação internacional na era do conhecimento. Brasília: CGEE, p. 53. PMCid:PMC2839321.

Katz, Sylvan. 1994. Geographical proximity and scientific collaboration. Scientometrics, 31(1): 31-43. http://dx.doi.org/10.1007/BF02018100

Keohane, Robert. 1984. After hegemony: cooperation and discord in the World Political Economy. Princeton: Princeton University Press.

Kerwin, Larkin. 1981. International Science: an overview. Science, 213: 1069-1072. PMid:7268414. http://dx.doi.org/10.1126/science.7268414

Krasner, Stephen. 1982. Structural Causes and Regime Consequences: Regimes as Intervening Variables. International Regimes, 36(2): 185-205.

Organização para a Cooperação e Desenvolvimento Econômico (OCDE). 2008. The internationalization of business $R \& D$ : evidence, impact and implications. Paris: OCDE.

Oszlak, Oscar e O’Donnell, Guillermo. 1995. Estado y políticas estatales en América Latina: hacia una estrategia de investigación. REDES Revista de Estudios Sociales de la Ciencia, 2(4): 99-128.

Salomon, Jean-Jacques. 1970. Science policy and its myths. Diogenes, 18(70): 1-26. http://dx.doi. org/10.1177/039219217001807001

Silva, Darly. 2007. Cooperação internacional em ciência e tecnologia: oportunidades e riscos. Revista Brasileira de Política Internacional, 50(1): 5-28. http://dx.doi. org/10.1590/S0034-73292007000100001 